\title{
Research on the graduate student quality monitoring of University of financial and economics
}

\author{
Shuoyi He $\mathrm{H}^{1, \mathrm{a}}$ \\ ${ }^{1}$ The Graduate School, Tianjin University of Finance and Economics, Tianjin, China \\ a1393271435@qq.com
}

\begin{abstract}
Keywords: postgraduate education, Quality control, Management by objectives, Process management.
\end{abstract}

\begin{abstract}
Graduate education in a country science and technology, economy, social progress and development plays an important role and influence.Education quality is the driving force of social development, it is the vitality of colleges and universities, is the individual competitiveness. With the expansion of the scale of education, quality problems naturally became the various countries' attention hot spot. Article on the analysis of the domestic research results and practice, on the basis of the objective management and process management in the face of graduate education quality monitoring are also proposed.
\end{abstract}

\section{Introduction}

At present, our country has obtained a master's degree and a PhD student nearly 2 million people, the total number of master's graduate students and doctoral students reading more than million, and rapid growth of two percent a year growth, become the world's second, second only to the power of graduate student training in the United States. Along with the continuous expansion of graduate student recruit students and education, the cultivation of the original mode and monitor mode has many can not adapt to the present phenomenon, the graduate education of our country all aspects of problems: lack of teachers; Curriculum system construction is not reasonable; Elimination rate is low, the graduate student appraisal system become a mere formality; Low scientific research innovation ability. On the premise of limited resources, build a scientific and reasonable and effective quality monitoring system of graduate education, through scientific management, strict monitoring, timely feedback strategies to improve the quality of graduate education has become the breach of the training unit to seek development.

\section{Foreign graduate students training quality monitoring research}

The British. British universities and colleges have greater autonomy, the teaching quality is mainly composed of responsibility, organizing academic experts and university academic freedom. Britain was originally by educational institutions to evaluate quality of graduate education, the university internal quality evaluation institutions is very perfect, from school to school, department, stratified by quality assurance and evaluation institutions.[1] Quality assessment committee rules: "self assessment is the self-criticism and analysis type, should be by those who have great knowledge in this subject, at the same time to undertake the most suitable position, can also evaluate the aims and objectives of the course and to complete."[2] In today's students obviously deficiencies, British university still uphold the principle of the screening of outstanding students from the sources, strict quality management to recruit students, create a good foundation for the next step of teaching training. Malcolm McRae, chairman of the British graduate student education association believes that if teachers eased graduate admissions standards, even if is admitted into the school, student because the former stage of the academic level is not up to standard and more effort, in order to make the students graduate and lower academic standards, even if they start to work, also do not have corresponding degree qualifications. 
Germany[3]. German higher education emphasizes the scientific research ability training, teaching take the impartment of directive manner, discussion-based, lab, and formed unique German mentorship training mode. Due to the shortage of funding, a doctoral candidate in most as a professor's assistant to participate in research, this is just the promotes the graduate student scientific research practice ability. On teaching almost few regular curriculum, more inclined to discuss in the process of scientific research, attach importance to experimental operation guidance and training, laboratory and lecture system is widely used to impart knowledge and research skills.[4]

In the construction of disciplines, Germany's graduate school is an interdisciplinary research group, the group has a clear research direction, take the student as the center, professor from different areas of academic disciplines. Doctoral student in graduate school can get the interdisciplinary scientific research practice guidance, interdisciplinary study, promote the discipline of mutual penetration.

\section{Provisions of University of financial and economics in China}

Shanghai University of Finance and Economics. A high level of discipline construction is the basis to improve the quality of graduate education. Shanghai university of finance and economics in advance the peak made on the basis of the subject development, construct advantage of the peak and plateau strategy; advance of graduate student education discipline layout; based on the demand of economic and social development, and strive to improve the structure of the secondary discipline; attaches great importance to the construction of professional degree graduate education base, efforts to promote the professional enrollments in and outside the enterprises or organizations to establish various forms of professional degree graduate education bases, form a combination of training mode. More interdisciplinary scientific research organizations and platform construction, and the construction of discipline group of interdisciplinarity, makes the organic combination of subject construction, scientific research and personnel training. Through continuous strengthening discipline construction, for high level of graduate education to lay the solid foundation for discipline.

Shanghai university of finance and economics in terms of strengthening quality control, introducing the international evaluation standard, the reform of quality evaluation mechanism, to adapt to different levels and types of graduate student training target, establish a scientific and standardized, multivariate composite quality evaluation mechanism. Strengthen quality management of cultivation process, strengthen the role of teaching steering committee, in self assessment on a regular basis; Set up quality information platform and the quality of graduate student information analysis and early warning mechanism, school graduate education quality report, released to the society regularly, take the initiative to accept social supervision.

Central University of Finance and Economics. Central university of finance and economics graduate department taking regular check and the way of periodic surveillance organization inspection and supervision work of graduate student teaching. Teaching inspection and supervision of content mainly includes: the teaching discipline, teaching quality; Graduate student attendance; The school rules and regulations implementation, etc. Regularly publish the teaching results, and feedback to the school and the parties concerned. For violation of the provisions of the teaching management must be paid to the minor criticism education, if the circumstances are serious, in accordance with the school regulations.

Zhongnan University of Economics and Law. At zhongnan university of economics and law in order to maintain the stability of teaching order, steadily improve the quality of teaching, cooperative schools of higher education evaluation center in graduate department and other relevant departments, according to the project of cultivating graduate students and the teaching plan, strict teaching of graduate courses by using the way of a variety of regular or not regular inspection, supervision and assessment, and gradually establish a perfect evaluation mechanism and index system, to check and evaluate the result of poor college and teachers, the school will shall be ordered to make rectification and processing, in accordance with the relevant regulations of the good, the school will give recognition and rewards.

Colleges in addition to actively assist the graduate division, the higher education evaluation and research center and other departments to complete a variety of teaching inspection, evaluation, also 
regularly carry out in line with the actual situation, the college teaching supervision and evaluation, comprehensive and timely to listen to the opinions of the students and teacher to understand various curriculum teaching, improve teaching quality.

\section{The problem of graduate education quality monitoring in our country}

Lack of quality culture. Compared with the traditional quality management concept, education quality assurance with particular emphasis on the establishment of the education quality culture and quality consciousness. But in our current education mode, there are a lot of traditional factors unfavorable to the growth of the education quality culture.

Quality of graduate student education in our country at present security work emphasized to evaluate promoting improvement, in the evaluation of promoting construction, combining evaluation and construction, the emphasis is on the principle of construction, hope to be able to let the school put the main energy into strengthening the internal construction and reform of colleges and universities management system and mechanism, in the evaluation work of identification of sexual function and diagnosis function, pay more attention to in the diagnosis of sexual function. However, seldom consider the allocation of educational resources, donated the school and the university entrance exam to college in the broader social fields such as how to make full use of the evaluation to build research and its conclusions. In practice, "to review construction", "to review and promote change" is often because the government assessment and attention, and investment, and improve, showing strong temporary and short-term. Someone called it "movement of paradigm". The external evaluation activities organized by the government of frequency is lower, and the school in a passive position, the initiative is hard to play, more time is only a state cope with even the opposite. [5]

The problems existing in the process management. The students quality problems. Between excellent students and individual professional distribution imbalance of graduate matriculate quality also is the main reason that reduces the quality of graduate education. The graduate student entrance exam also focused more on exam-oriented education, neglecting to enter oneself for an examination the graduate student's comprehensive study. First of all, the more value in the graduate student enrollment is the first try achievement, requirement for graduate students comprehensive quality is not high, lead to some higher comprehensive quality, professional development potentiality, but first try play undergraduate students failed to be admitted mistakes; Again, the graduate student enrollment expansion of scale makes some fewer enter oneself for an examination, students are not ideal postgraduate training units, had to be disguised to decrease the difficulty of professional class exam improve students ways to attract more undergraduate students to enter oneself for an examination of the first grade, the lower the difficulty of postgraduate entrance is also will affect the training quality; Finally, the change of graduate applicants graduate school motivation is also the cause of the decrease of the quality of the students. Many candidates attend graduate school is not in order to improve their academic ability, but the key of it as a piece of work, and so their main focus is not on learning. Government officials, enterprise old total graduate increasing phenomenon also reduces the quality of students.

Teacher-team construction. Relative to the expansion of postgraduate admission scale, the number of teachers growth is slow, so each mentor to guide the number of graduate students in grow in quantity, part of the training unit and even the emergence of a more than 20 teachers to be responsible for guiding the graduate student's situation. Mentor's energy is limited after all, so there is no guarantee that every time the guidance of graduate students and guidance quality. In addition, under the impact of the market economy, some graduate tutor in pursuit of economic benefits in the enterprise, part-time gradually abandoned their own academic level, graduate student cannot get a good academic guidance.

With the rapid development of postgraduate education, due to the short of teachers, low structural shortages, frontier, tutor especially lack of leadership type, there are many more teachers in guiding process due to insufficient energy, time and so on investment, to some extent, affect the quality of the graduate cultivation, also restricts the development of graduate education level. 
Curriculum Construction. The graduate student curriculum more is for the sake of longitudinal, namely according to the professional training goal to set up the professional training plan of professional curriculum, and think too much about the professional therefore focused on cultivating "know-how" not qualified "generalist". Courses are divided into degree courses (including public degree courses and professional degree courses), required courses and elective courses, they were not quite reasonable, the ratio between the relationship didn't handle. And the course requirements are rigid, lack of flexibility, so some courses deviate too much, this paper, the time from both the graduate students do also makes other courses should be arranged eventually not arranged into the program. Some professional training program was arranged into the correlation between the professional and is not big, but with the training unit overall discipline characteristic relation of course, this is also not give full consideration to their own professional knowledge structure of demand. Professional course FengBiHua is unreasonable phenomenon of the curriculum. Some train unit will be the same and different research direction graduate student set up different curriculum, on the surface, this is the embodiment of the graduate student course management refinement, but it is not, it will cause the same closeness between different professional direction students, due to the limitations of their professional knowledge.[6]

In addition, in the course of actual teaching, the teacher use heuristic, discussion, exploratory teaching method is very rare, is more of a scripted flexible teaching. Neither feedback according to graduate students in the information to the appropriate teaching methods and means of improvement, the reasonable adjustment, there is no combining the reality of graduate students to master professional knowledge according to their aptitude, thus causes the student always acceptable in a passive state, could not mobilize the learning enthusiasm and initiative of graduate students, make the graduate student's innovative potential is not scientific mining, nature also won't be able to cultivate innovation ability, high comprehensive quality of graduate students.

\section{Improve the quality of graduate education, monitoring proposal}

Target management level. The discipline construction direction. Attaches great importance to the construction of three, further integration and optimization of subject resources, improving the structure of the subject, the formation of a multidisciplinary coordinated development, besides, one of mutual promotion discipline innovation system; Formation of the preponderant discipline and characteristic discipline unifies, basic discipline and applied discipline, the combination of traditional and emerging disciplines to promote, competitive and sustainable development ability of discipline advantage as a whole. Give full play to the exemplary and leading role of key subjects, to strengthen the construction of emerging disciplines basic conditions and strive to cultivate more high quality talents for the society.

According to their aptitude, science to develop training plan. A greater difference between graduate management and management undergraduate and graduate students autonomy more time learning stage, thus unified management difficult, often cannot "one-size-fits-all."

On the premise of groundwork, outstanding professional characteristics, in the professional courses, colleges and universities need to according to the research direction of the professional targeted selection more scientific research and production practice in life, practical courses, to reduce some of the basic course and set theory.

Experience undergraduate studies and training, graduate student has to have certain professional knowledge accumulation, at the same time, there are quite a self-study ability, and the ultimate goal of graduate education is to carry high-level innovative talents for the country, therefore in the curriculum should emphasize on the depth of knowledge and the frontier of knowledge. Our country existing graduate professional courses more or less have the problem of aging. For disciplines basic knowledge and theory, using the method and formula, experience the axioms and theorems are basically not update or update speed is not fast, but most of these contents should have in undergraduate phase, should not occupy a large class of the postgraduate stage. Given the goal of graduate education, practical and innovative, teachers need to adopt the fixed teaching material, but will need to master the basic knowledge and theory of the origin of the content such as told students 
access to information by the students themselves, or to a student self-study after finishing, and organize regular class problems encountered in the process of students' self-study of answering questions to answer; Courses should focus to academic point of view, theoretical achievements and latest technology as the main content, academic discussion or seminar as the main form, and will inform the students of the content of the study or discussion in advance, so that the students access to relevant data, enhance the understanding of course content and thinking, also is helpful for students to participate in the discussion, make its creative thinking development, scientific research ability was improved.

Process management level. Teachers' work quality level. Colleges and universities on the one hand, should adhere to the academic standards as the basis of teacher team construction and the important premise, innovation science teacher evaluation and selection mechanism, hire tutor, in strict accordance with the academic standards and in strict accordance with the assessment of teacher education standards, solve the teacher can only "work", not "class", as well as mentor to the graduate student's academic guidance does not reach the designated position. Should introduce the humanistic management thought, on the other hand, the construction of the contingent of tutors, advocacy of flexible management, pay attention to the emotional communication; Advocate giving full play to the advantages of team, encourage interdisciplinary; Respect teacher's subject consciousness, by using flexible incentives, fully mobilize the enthusiasm and initiative of mentor.

In terms of raising the academic level of teachers, we should strengthen the cultivation of the existing teachers, in addition to improve the existing teacher education level, each year should organize regular teachers to go abroad for further study or to the country with a high professional level of other colleges and universities for learning and communication; Second, the organization and to participate in a high level of academic conferences at home and abroad, to increase the opportunity to communicate with the outside world, and expanding the teachers' way of thinking and vision, update guidance teacher's knowledge level and the content, encourage teachers to master academic frontiers.

Course construction level. The ministry of education "about implementing postgraduate education innovation plan, strengthening the innovation ability training of graduate students and further improve the training quality of several opinions, points out that the science and education for the implementation of strategy and the strategy of reinvigorating China through human resource development, postgraduate education to strengthen the cultivation of innovative consciousness, innovative spirit and innovative ability, this is the requirement of social development and The Times. As a result, the graduate student curriculum system should be toward to the training of the creative talents to build. 1995 national science, engineering and public policy committee issued "the reshaping of the scientists and engineers graduate education" pointed out: science and engineering graduate student education is not only to provide the basis of the development of science and engineering strength, but also meet the following requirements: ". 1.To satisfy the students who don't work in the scientific research and academic future needs; 2. To provide more academic options, in order to avoid excessive specialization; 3 . To promote the government and other department staff communication, interpersonal and teamwork skills. While in the field of science and engineering are discussed in this report, but we felt that we apply to other areas, including the humanities domain."

We should not only cultivate the academic and research talents, to cultivate applied, compound talents; We should cultivate not only scientific knowledge innovation talent such as masters and scientists, but also cultivate a large number of enterprise technology and public services to technology innovation, system innovation and management innovation of professional master, engineers and management personnel.

Student management level. The teaching supervision system. In the process of graduate education, the school hired a higher academic level and teaching experience, strong sense of responsibility and the dedication to work of retired old professor supervisor for the teaching. Supervisor is responsible for supervise and guide the teaching management and the implementation of the teaching reform scheme and implement; Supervise and urge the completion of teaching tasks on time with good quality; Urge guide interdisciplinary teaching plan formulation, implementation; Responsible for the 
discipline construction, curriculum construction, teacher training, teaching quality assessment work; Collection, analysis, research, teaching the opinions and Suggestions for the work of teaching management, and report to the superior.

A class system. School for teaching implementation should formulate relevant measures of leaders at all levels put forward specific requirements in class, listen to the teacher and asked the leadership to make records, late for feedback, improvement opinions are put forward. Schools not only requires the leadership class, responsible for the student management in the grass-roots workers to actively participate in class, such as counselors, teachers, many aspects, a full range of teaching information collection, feedback in time.

\section{References}

[1] Pan Wuling. Graduate education quality evaluation system research in China [D]. East China normal university, 2004.

[2] Wen Dawei. Doctor, master's degree authorization store assessment system and method of research and practice [D]. Central south university, 2003.

[3] Chtistina georgina rossetti.british poetess Kenneth Xu Bei. USA: graduate recruit a sharp growth in the us [J]. Journal of foreign graduate student education. 2011, (16) : 8-9.

[4] Shi Lanxin, yong-ping Chen. Comparison of graduate student training mode at home and abroad and study [J]. Journal of southeast university (philosophy and social sciences edition), 2010 (2) : 117-122.

[5] Shi Lei.Graduate education quality evaluation and quality assurance system research[D]. university of science and technology of China, Ph.D. Thesis, (2010)

[6] XiaoPeng. Introduction to the quality of graduate student education in local colleges several problems and countermeasures [J]. Journal of business review. 2013 (1) : 236-237. 